\title{
RELIABILITY OF PROTOTYPE VERTICAL AXIS WIND TURBINE
}

\section{COMPONENTS SELECTION}

\author{
K. MANIKANDAN ${ }^{1} \&$ B. JUSTUS RABI ${ }^{2}$ \\ ${ }^{I}$ Research Scholar, JNT University Hyderabad, Telangana, India \\ ${ }^{2}$ Principal, AACEE, Chennai, Tamil Nadu, India
}

\begin{abstract}
The papers mainly focus the power electronics application for Wind turbine testing. Wind turbine system reliability has been determined based on identifying the components, it improves system performance. In vertical axis wind turbine testing varies with the selection of generators and converters. Efficiency of wind turbine compared all the wind turbine component, rotor, direct drive permanent magnet generator, and power electronics converter efficiency should be compared overall wind turbine efficiency.

KEYWORDS: Wind Turbine, Reliability, Power Electronics Components \& Product Differentiation
\end{abstract}

Received: Apr 15, 2018; Accepted: May 07, 2018; Published: Jun 07, 2018; Paper Id: IJEEERJUN20183

\section{INTRODUCTION}

In Modern world wind turbine power Wind turbine Reliability is a measure of permanent magnet generator and power rectifier and inverter and controller components efficiency over the expected lifetime of the product. Concerned with probability and frequency of failures. Reliability is a prediction of the future. Under Steady State, define the chance of failures at a particular period of time Reliability is one of the most important elements of test quality. Reliability Evaluation test using a different technique involved in different components. Reliablity modeling of permanent magnet generator, power converter components. Mainly three factors affecting the reliability of vertical axis wind turbine testing, design factors, Complexity and Stress.

\section{RELIABLITY ANALYSIS}

Power converter depends on thermal model of IGBT and diodes, failure rates of IGBT, diode and capacitor. Mainly wind turbine power loss, based on components efficiency. A reliability block diagram is a drawing and calculation tool used to model the complex system. It used we can calculate failure rate, MTBF, reliability, and availability of the system can be calculated. This fault tree analysis is a systems approach to performing reliability analysis of PE equipment and is the main focus of this report. The PE reliability analysis process starts with collecting information necessary to create a system reliability model in the form of a fault tree. The tree traces the logical connection between primary failures and system failures.

In General power electronics components fall into main three periods, infancy, normal operating life and wear out. 

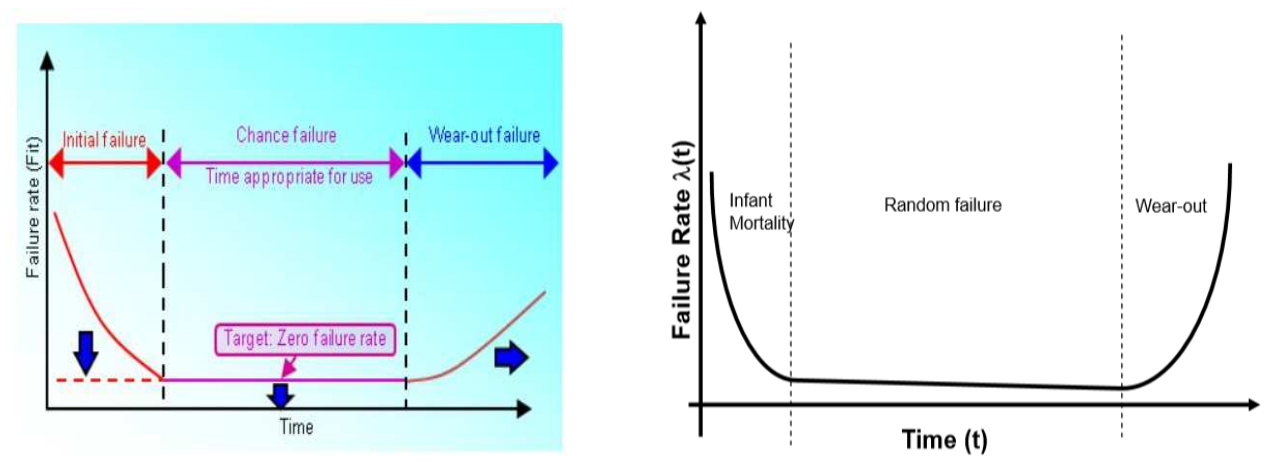

Graph 1: Basic Reliability Structure

Above diagram says, the repeatability of findings, the finding periods, it is divided into three categories initial failures, the chance of failures and wear out failures a different scenario. Or observing behavior.

IGBT is a semiconductor device, nowadays it is suitable for most of the power electronics applications. IGBT is a Solid state device, Voltage controlled device. Selection of the IGBT is based on operating voltage, switching speed, usable frequency and withstand capability. IGBT drive is key role act on a between power transistor and controllers. This selection of driver and output power desired the reliability of converter solution. IGBT driver circuit, input power depends on the key parameter is the gate charge.

\section{Wind Energy Electronics Failures}

A wind turbine converts the kinetic energy from wind into Mechanical energy and converted into Electrical energy. There are two main categories based on the rotating axis position. Which are Vertical axis wind turbine (VAWT) and Horizontal axis wind turbine (HAWT). A set of wind turbine rotor blades, create a force, it turns to torque on the shaft It is connected to a Permanent Magnet generator and the electrical equipment's. The generator generates a variable voltage which is converted to a fixed voltage by using power electronics converter. A constant rotor speed maintains the same rotational speed while the wind mills generating energy and A variable speed rotor tries to achieve the optimum rotational speed for each wind speed, maintaining constant the optimum tip speed ratio will ensure optimum efficiency at different airspeeds. Following parameters considered in wind turbine design.

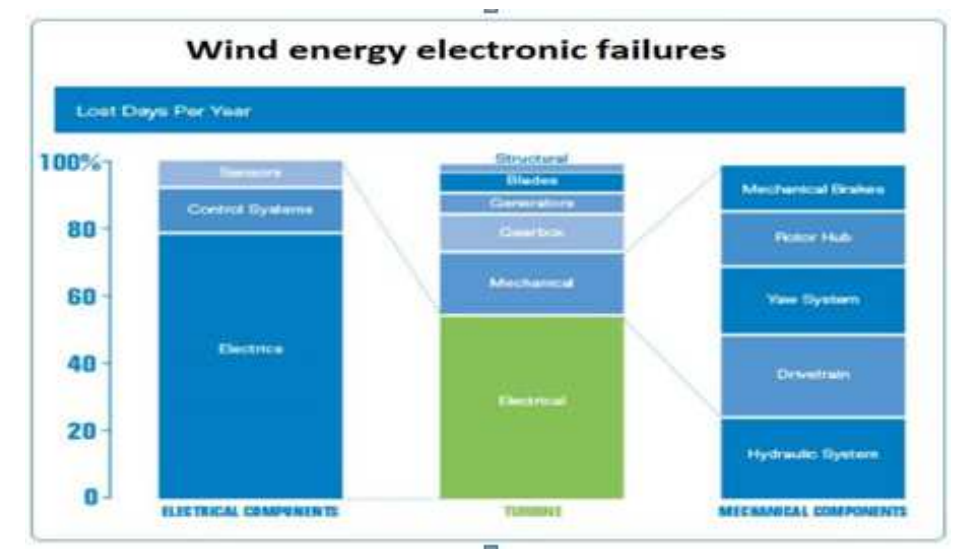

Figure 1: History of Wind Energy Electronics Failures

- Wind Speed,

- Number of Blades, 
- Air density,

- Moment of Inertia,

- Blade length,

- Rotor Size.

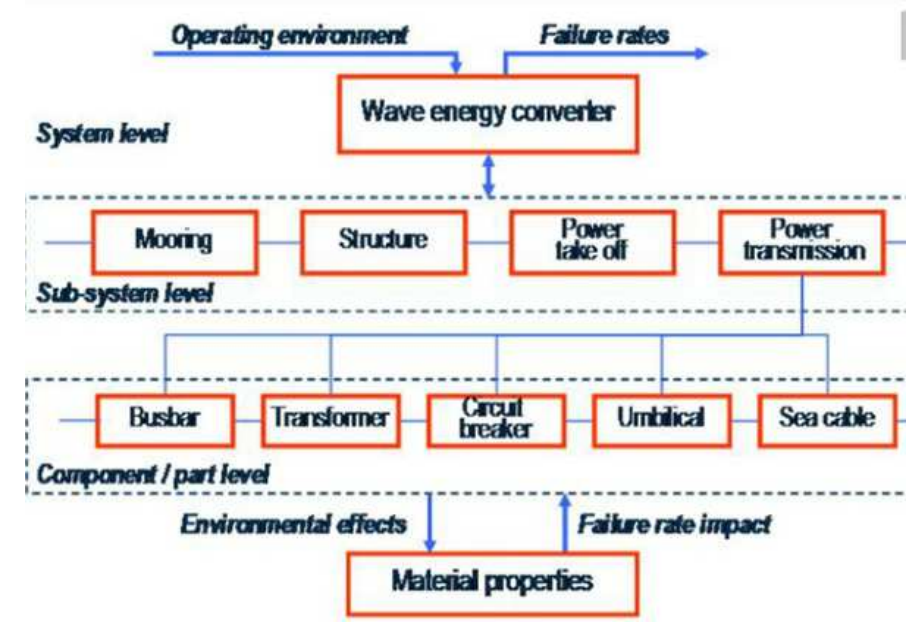

Figure 2: Basic Wind Energy Converter

\section{Reliability of Components Selection for VAWT}

Vertical axis wind turbine collecting energy from all directions. This 2KW Power curve of VAWT cut in speed at $2 \mathrm{~m} / \mathrm{s}$ at every position. The permanent magnet generator size and dimension should be matched with VAWT Rotor. In motor materials affect the generator performance, core ferromagnetic materials, permanent magnet materials, magnet wires and winding insulation. Different rotor configuration, permanent magnet and materials and Geometry designed by using RMxprt software. NdFe magnet has higher remnants. Samarium cobalt magnet has high temperature ratings. Magnetization and energy product. Generator should be designed using specially selected material and treated to resist corrosion and oxidation. The Power semiconductor devices had a fast-moving technology. This technology and results rapidly launch, self and force commutated devices,ie Metal-oxide semiconductor field effect transistor (MOSFET) and Insulated Gate Bipolar(IGBT) and Gate Turn off Thyristor (GTO) and Mos-Controlled Thyristor(MCT) More concentration of application developments has been increasing due to Rapid developments of power electronics and Control Processor technology ie Microprocessor and Microcontroller, Digital signal processing.Those high performance given by Silicon or silicon carbide. This power electronics and power system combination consisting of a Power converter, load unit, Isolation unit and a control unit. Power converter power flow may in both direction, dependent on topology and applications. 


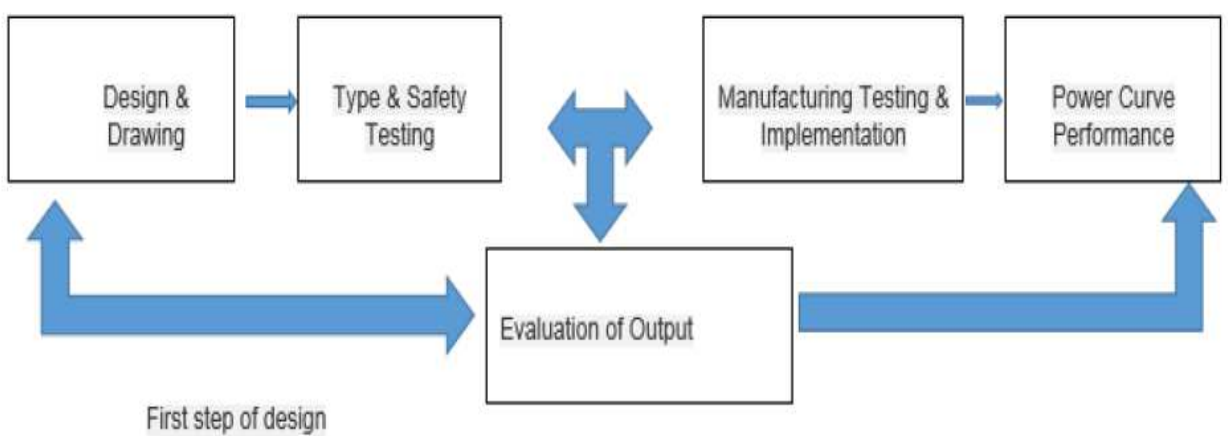

Figure 3: Basic Simulation Diagram

\section{Test Bed by using Variable Frequency Drive}

Variable Speed Drives (VFD) is that controlling the speed and rotating force of a Motor. The VFD contains three pairs of IGBT,s and Transistors and Pulse width Modulation control circuit. Each IGBT can generate sinewave output each time of conduction. Linear relationship between load horsepower and with increases in RPM. VFD Reliability based on torque characteristics, insulation stress, temperature rise, bearing current, noise level and vibration level. Then cable selection VFD to the motor, the rise time of the VFD output voltage pulse and the size of the motor full load current plus overload.

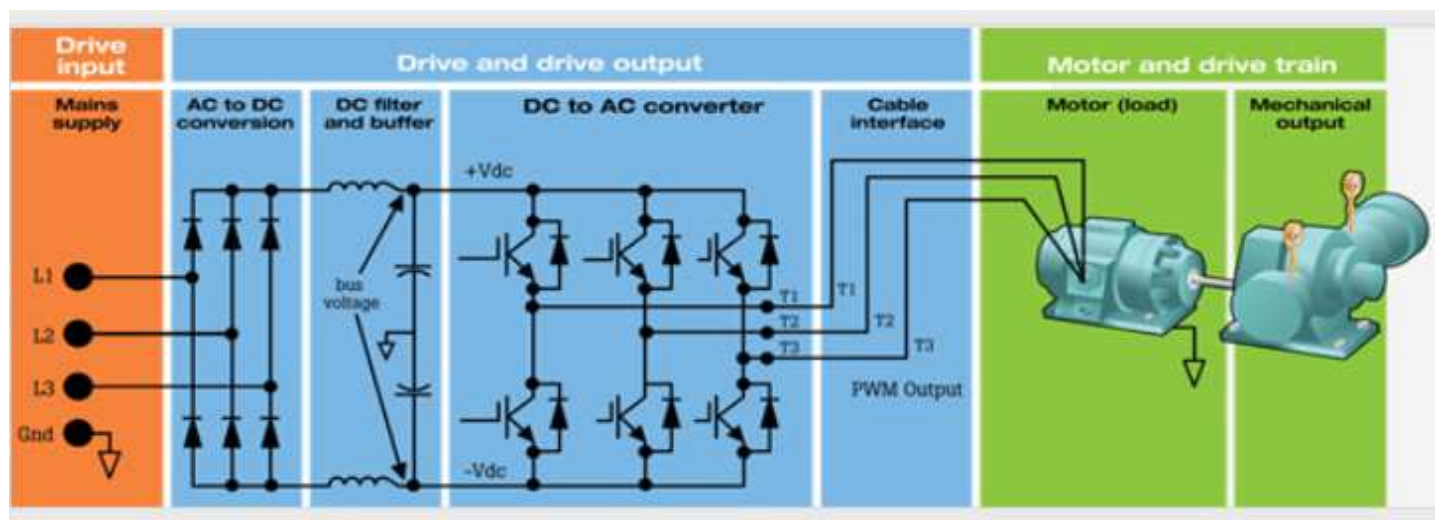

Figure 4: Basic VFD Connection with Motor

\section{Permanent Magnet Generator (PMSG)}

Permanent Magnet Generator converts Mechanical power into Electrical Power.

Omni wind turbine Rated Mechanical Power - 2kw

Omni wind turbine Rated Apparent Power- $2.2 \mathrm{Kw}$

Rated Line VolatgeRated Line to Line Voltage- $230 \mathrm{~V}$

Rated phase voltage-440V

Rated Rotor Speed:150-450RPM

Number of Pole Pairs: 36

Omni wind turbine Cut-In Wind Speed- $2 \mathrm{~m} / \mathrm{s}$ 
Omni wind turbine Rated wind Speed- $12 \mathrm{~m} / \mathrm{s}$

Omni wind turbine Number of rotor blades-3

Omni wind turbine Rotor Axis: Vertical

Omni wind turbine Rated Speed: 600 rpm

\section{Wind Turbine Rectifier}

Multilevel Voltage source Converter Type

Frequency Modulation PWM $1 \mathrm{KHz}$ to $20 \mathrm{KHz}$

\section{Wind Turbine Power Inverter}

Multilevel Converter Type

Frequency Modulation PWM $1 \mathrm{KHz}$ to $20 \mathrm{KHz}$

DC Link capacitor and Filter

\section{Consideration of Wind Turbine Test Bed}

Test bed design consists of Motor, wind turbine rotor and blade and VFD Set up. Rotor Self-starting is wind speed $3 \mathrm{~m} / \mathrm{s}$ It is implies less weight and high Torque of rotor components design. VAWT Test design conducted both fee running and load conditions. Wind turbine handbrake used for wind speed go up normal condition and power controller failure condition. VFD Monitoring and controlling the speed of machine, it has adjust manual intervention for this testing. VFD connection is three-phase, so three phase motor only suitable for this kind of omni vertical axis wind turbine testing.

\section{Induction Motor Speed Calculation Formula:}

Synchronous Speed $(\mathrm{Ns})=120 \times$ Frequency $(\mathrm{F}) /$ Number of poles $(\mathrm{P})$

Horse Power $(\mathrm{P})=$ Speed (in RPM) x Torque / 5252.

Power increase cube proportion to the speed:

Tabe 1: Comparision of Three Brand Product

\begin{tabular}{|l|c|c|c|c|}
\hline \multirow{2}{*}{\multicolumn{1}{|c|}{ Parameter }} & \multirow{2}{*}{ Units } & \multicolumn{3}{c|}{ Company } \\
\cline { 3 - 5 } & & $\mathrm{X}$ & $\mathrm{Y}$ & $\mathrm{Z}$ \\
\hline Rated Output Power & $\mathrm{KW}$ & 1.5 & 1.5 & 1.5 \\
\hline Rated Speed & RPM & 100 & 550 & 100 \\
\hline Rated output Voltage & VAC & 220 & 220 & $380 / 220$ \\
\hline Rated Current & $\mathrm{A}$ & 3.94 & & $2.4 / 4.1$ \\
\hline Phase Resistance & $\Omega$ & 5.1 & 0.3 & \\
\hline Efficiency & & $85 \%$ & $93 \%$ & $85 \%$ \\
\hline
\end{tabular}




\section{X1 - Power (W) Vs RPM}

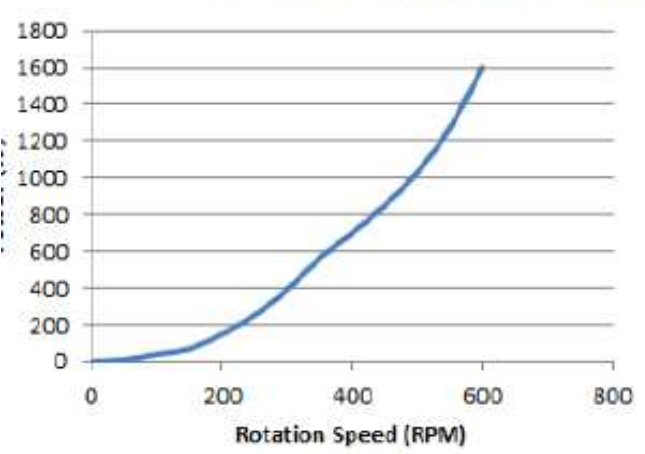

Graph 2: Power Vs RPM

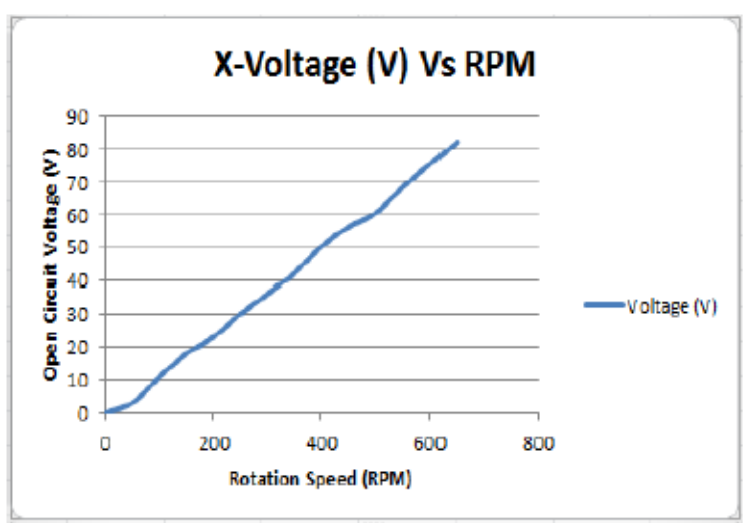

Graph 3: Volatge VS RPM

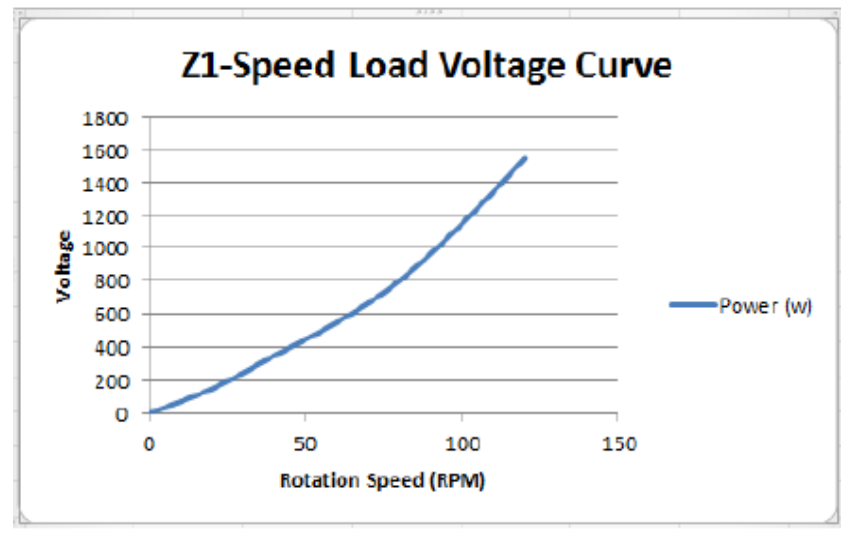

Graph 4: Volatge VS Speed Curve

\section{RELIABILITY TESTING CALCULATOR}

Based on design calculation, enter the component's data into the below table, which is developed by ALDSI. MTBF is a free version of Reliability checking calculator

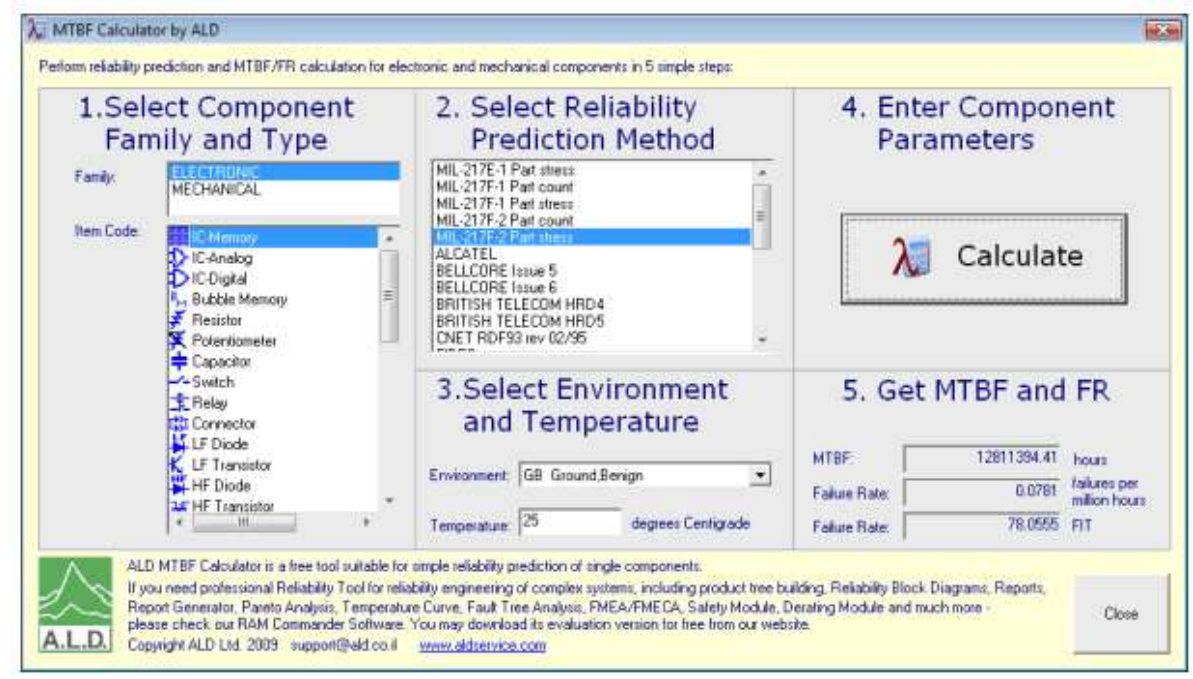

Figure 5: MTBF Calculator Tool 


\section{CONCLUSIONS}

This paper proposed a reliability three-phase wind turbine power circuit efficiency varying efficiency based on components selection by using that MTBF calculator. Main system and subsystem components also have to improve and design expectation also improved. Add on rectifier efficiency, PMG efficiency and Power inverter efficiency should be getting on the original efficiency of wind turbine systems.

\section{REFERENCES}

1. http://earthship.com/vertical-axis-wind-power-generation-prototype

2. MdRabiul Islam*,YouguangGuo, and Jianguo Zhu "Power converters for wind turbines: Current and future development" Materials and processes for energy: communicating current research and technological developments (A. Méndez-Vilas, Ed.) 2013.

3. Jorge Antonio VillarAlé, Gabriel da Silva Simioni, João Gilberto AstradaChagasFilho "PROCEDURES LABORATORY FOR SMALL WIND TURBINES TESTING” European Wind Energy Conference \& Exhibition 2010.

4. https://aldservice.com/Reliability-Software/free-mtbf-calculator.html 
